MATHER, x. 1953. Genetical control of stability in development. Heredity, 7, 297-336.

REEVE, E. C. R. 1960. Some genetic tests on asymmetry of sternopleural chaeta number in

Drosophila. Genet. Res., 1, 151-172.

REEVE, E. C. R. 1961. Modifying the sternopleural hair pattern in Drosophila by selection. Genet. Res., 2, 158-160.

THODAY, J. м. 1958. Homeostasis in a selection experiment. Heredity, 12, 401-415.

\title{
A NOTE ON SOMATIC SEGREGATION OF THE SPECTACLE PATTERN IN POTATOES
}

\author{
N. W. SIMMONDS \\ Scottish Plant Breeding Station, Pentlandfield, Roslin, Midlothian
}

Received 5.vii.73

\section{SUMmary}

The behaviour, over 3-8 generations of vegetative propagation, of nine potato clones showing variable expression of the spectacle pattern is described. Clones differed in expectation of spectacle frequency at equilibrium from 4 to 88 per cent. Variation in spectacle expression depended more upon undefined internal factors than upon environment.

\section{INTRODUCTION}

THE work reported here is a continuation of studies of variable spectacle patterns on potato tubers described earlier in this journal (Simmonds, 1965). The materials used were the same four cultivated tetraploid (Andigena Group) potato clones as before, with the addition of five clones newly selected from Andigena seedling populations.

\section{Results}

\section{(i) Distribution of spectacle frequencies}

The equilibrium frequency of spectacles $(s p t)$ in a stock depends upon the frequencies of $s p t$ tubers among the tubers produced by spt (say $p$ ) and by non-spt (say $r$ ): equilibrium, which is independent of initial frequency, is at $r /(1+r-p)$ (Simmonds, 1965). Data for nine clones are summarised in table 1 and show that expected equilibria range very widely from 4 to 88 per cent. In eight cases $p$ exceeds $r$, generally very widely, but in one clone (63/87) $r$ slightly exceeds $p$, though presumably only as a freak of sampling. For the clone $62 / 232$ estimates of $p, r$ and equilibrium previously published agree poorly with results in table 1 , based on much more extensive observations. The difference is due to sampling and reflects the variability between plants which is characteristic of the material. It was only in the fourth generation that any spt tubers were produced at all in the non-spt line and the estimate of $r$ was much influenced by the subsequent appearance of relatively few plants with high spt frequencies. This behaviour, and the converse, has been noted several times and presumably reflects a change in potentiality for spectacle development early in the life of the young sprout. 
It will be seen from table 1 that three clones have been grown for eight vegetative generations and thus give opportunity to examine the relative

\section{TABLE 1}

Nine potato clones showing variable spectacles. In body of table, spectacle tubers percentage with, in brackets, total numbers of plants and of tubers borme by them upon which the entry is based. For explanation of last column see text

\begin{tabular}{lcccc} 
Stock & Generations & $\begin{array}{c}\text { Tuber progeny of plants raised } \\
\text { from tubers that were }\end{array}$ & $\begin{array}{c}\text { spt } \\
\text { percentage } \\
\text { at }\end{array}$ \\
\cline { 3 - 4 } $62 / 191$ & 6 & $2 \cdot 5(59 ; 526)$ & $40 \cdot 2(32 ; 246)$ & $\begin{array}{c}\text { spt } \\
\text { equilibrium }\end{array}$ \\
$62 / 231$ & 8 & $19 \cdot 7(42 ; 213)$ & $64 \cdot 9(40 ; 191)$ & $35 \cdot 0$ \\
$62 / 232$ & 8 & $18 \cdot 6(39 ; 290)$ & $92 \cdot 2(46 ; 412)$ & $70 \cdot 5$ \\
$62 / 235$ & 8 & $27 \cdot 8(50: 540)$ & $78 \cdot 1(53 ; 649)$ & $55 \cdot 9$ \\
& & & & \\
$63 / 87$ & 3 & $60.5(13 ; 114)$ & $44 \cdot 8(17 ; 181)$ & $52 \cdot 2$ \\
$63 / 136$ & 3 & $30 \cdot 2(17 ; 129)$ & $47 \cdot 3(16 ; 112)$ & $36 \cdot 4$ \\
$63 / 138$ & 6 & $18 \cdot 4(30 ; 244)$ & $71 \cdot 0(33 ; 241)$ & $38 \cdot 8$ \\
$64 / 175$ & 3 & $59 \cdot 1(7 ; 22)$ & $92 \cdot 1(11 ; 38)$ & $88 \cdot 2$ \\
$64 / 335$ & 4 & $57 \cdot 3(20 ; 96)$ & $83 \cdot 3(19 ; 90)$ & 77.4
\end{tabular}

importance of season and other factors in determining spectacle frequencies. Clones $62 / 231,232$, and 235 were grown exactly in parallel so that place and time of cultivation were the same for all three; 62/191 was started a generation before the others, so only five generations were exactly parallel as between all four clones. In addition, five clones (62/231, 232, 235, $63 / 138$ and 64/335) were grown in parallel for four generations. Three useful sets of comparisons were therefore possible: 3 clones $\times 8$ generations, $4 \times 5$ and $5 \times 4$. The percentages of spt tubers in the total produce of all plants raised from tubers of like phenotype in any one clone/generation were

TABLE 2

Analysis of variance (angles) of spectacle frequencies by generations and clones
(see text)

analysed after angular transformation. Total numbers of tubers upon which each percentage was based varied rather widely and many percentages approached zero or 100; the analysis is therefore not above reproach and must not be pushed too far. Results (table 2) show that effects of clones (C), tuber phenotypes $(T)$ and their interactions are the most important source of variation; effects of generations $(G)$ and their interactions are generally smaller. Another way of testing the effect of environment is to look for correlations between spt and non-spt lines within clones between generations; none was apparent. 
Since differences between generations included different seasons and places (glasshouses at Hertford and Edinburgh), the conclusion is that spectacle expression is largely dependent upon (undefined) internal factors, much less upon environment: and this agrees with the earlier observation that variation of temperature of cultivation is the range $15^{\circ}-25^{\circ} \mathrm{C}$. was without detectable effect (Simmonds, 1965).

\section{Discussion}

The non-spt phenotype in this work is the same as "hidden spotted" of Howard $(1964,1967)$; it consists of a ground (cortex) colour plus periderm splashes round the eyes. From Howard's work, it looks as though the great majority of hidden spotted potatoes are constant under ordinary tuber propagation, though the potential for spectacle expression is readily revealed by eye-excision or irradiation. Unassisted variability of expression is uncommon, even rare: the nine clones reported upon in this note were drawn from many thousands of Andigena plants and were specifically selected for variability of expression.

In terms of $p$ and $r$, the situation may be summarised as follows:

$\begin{array}{lccc} & p=0 & 1<p>0 & p=r=1 \\ & r=0 & 1<r>0 & \\ \text { Equilibrium (spt\%) } & 0 & 1-99 & 100 \\ \text { Phenotype } & \text { Stable } & \text { Variable } & \text { Stable } \\ & \text { non-spt } & s p t & s p t \\ \text { Frequency } & \text { Frequent } & \text { Rare } & ? ? ?\end{array}$

\section{REFERENCES}

HOWARD, н. w. 1964. Further effects of the pigment restricting gene $\mathbf{M}$ in potatoes: hidden spotted and spectacled. Heredity, 19, 349-56.

HOWARD, H. w. 1967. Differentiation in potatoes: hidden spotted and spectacled. Heredity, $22,57-64$.

smMoNDs, N. W. 1965. Somatic segregation of the spectacle pattern on potato tubers. Heredity, 20, 277-88. 